\title{
CARACTERÍSTICAS DE PACIENTES COM PERMANÊNCIA SUPERIOR A 24 HORAS EM UMA UNIDADE DE PRONTO ATENDIMENTO DO OESTE DO PARÁ
}

\section{ARTIGO ORIGINAL}

REGIO, Gabriela Leusin ${ }^{1}$

REGIO, Gabriela Leusin. Características de pacientes com permanência superior a 24 horas em uma Unidade de Pronto Atendimento do Oeste do Pará. Revista Científica Multidisciplinar Núcleo do Conhecimento. Ano 05, Ed. 07, Vol. 05, pp. 5271. Julho de 2020. ISSN: 2448-0959, Link de acesso: https://www.nucleodoconhecimento.com.br/saude/pacientes-com-

\section{permanencia}

\section{RESUMO}

Este estudo leva em consideração o atendimento na UPA 24hs de Santarém/PA no que tange a permanência dos pacientes em período superior a $24 \mathrm{~h}$, despertando 0 interesse em mapeá-los por meio de uma amostra resultante de 289 pacientes no período de junho, julho e agosto do ano de 2019, oportunizando uma visão holística para uma análise da eficácia desta política de saúde considerando os indicadores epidemiológicos, hospitalares e demográficos obtidos. Por meio do prontuário de cada paciente foi possível identificar a data de admissão, o diagnóstico médico e sua correlação com as categorias da CID-10, data e motivo da saída/alta, bairro e idade dos pacientes que estiveram em observação/internados na unidade, sendo consideradas as salas de Observação Adulto/Amarela, Observação Pediátrica e Sala de Urgência/Vermelha. Como resultado do estudo de caso evidenciou-se o maior tempo de permanência na Sala de Urgência, onde a média foi de 3,76 dias, todavia a média das 3 salas de observação foi de 3,16 dias. O bairro que apresentou maior

\footnotetext{
${ }^{1}$ Especialista em Gestão em Saúde (Fiocruz-2019), Tecnóloga em Marketing (Fatec Internacional-2011), Graduanda em Administração (Claretiano - 1ํo semestre/2020).
} 
percentual de incidência entre os pacientes foi o Bairro Planalto com 9,86\%. A Sala de Urgência no mês de junho representou $41,66 \%$ de pacientes, sendo este, o maior percentual de permanência entre os períodos e salas de observação/internação. Quando analisados isoladamente, identificou-se a permanência de até 12 dias na referida sala. Com relação a alta dos pacientes, o motivo Residência/Domiciliar atingiu o maior percentual dentre os demais motivos, obtendo $70,66 \%$ em junho. A categoria diagnóstica CID-10 de maior prevalência foi a de Doenças do Aparelho RespiratórioCID J00-99, onde a média geral das 3 salas nos meses em estudo foi de $37,51 \%$. Houve a predominância do sexo masculino dentre os pacientes representando $50,88 \%$. A média das 3 salas indicou a faixa etária acima de 60 anos com maior predominância, sendo $41,90 \%$. O referido trabalho possibilitou, ainda, conhecer a oferta de serviços e interação entre as políticas públicas de saúde almejados na Rede de Atenção à Saúde-RAS e Rede de Atenção às Urgências-RAU.

Palavras-chave: Unidade de Pronto Atendimento, tempo de permanência, redes de atenção às urgências, redes de atenção à saúde.

\section{INTRODUÇÃO}

Há quase 30 (trinta) anos um novo marco na história da saúde dos brasileiros se consolidava. Em 19/09/1980 por meio da promulgação da Lei nㅇ 8080, mais conhecida como a Lei Orgânica do SUS-Sistema Único de Saúde, iniciava-se a garantia do acesso à saúde universal a todos, de forma não contributiva, sem discriminação de cor, raça ou condições sociais. Com financiamento oriundo de impostos dos cidadãos brasileiros cabendo ao governo federal a implementação das políticas nacionais e, a governabilidade nas instâncias estaduais e municipais pelos gestores públicos de saúde.

De acordo com o Ministério da Saúde "o SUS é o único sistema de saúde pública do mundo que atende mais de 190 milhões de pessoas, sendo que $80 \%$ delas dependem exclusivamente dele para qualquer atendimento de saúde". (MINISTÉRIO DA SAÚDE, 2019). 
Numa visão estratégica global do Ministério da Saúde-Portaria GM n 4.279 de 30 de dezembro de 2010 evidenciamos a Rede de Atenção à Saúde, cujo foco é a integralidade do cuidado da população, na promoção da saúde integral, de qualidade e, contínuo em diferentes níveis de atenção em consonância com as diretrizes do SUS.

Como política de saúde interposta à Atenção Básica e a Hospitalar está a UPA, objeto deste estudo, sendo componente da Rede Organizada de Atenção às Urgências, conforme normativas instituídas pela Portaria no 1.601 de 7 de julho de 2011 que "Estabelece diretrizes para a implantação do componente Unidade de Pronto Atendimento (UPA 24h) e o conjunto de serviços de urgência 24 horas da Rede de Atenção às Urgências, em conformidade com a Política Nacional de Atenção às Urgências". (BRASIL, 2011).

Referencia-se, ainda, a Portaria 1600/2011 cujo teor do Art. $1^{0}$ "Reformula a Política Nacional de Atenção as Urgências e institui a Rede de Atenção às Urgências no Sistema Único de Saúde (SUS)”. (BRASIL, 2011).

Uma das propostas da existência das Unidades de Pronto Atendimento é acolhimento e a permanência dos pacientes em observação no período máximo de $24 \mathrm{~h}$, e, se necessário, dar continuidade ao tratamento junto a RAS - Rede de Atenção à Saúde, proporcionando cuidado integral, atendimento humanizado e fazendo uma gestão eficiente dos recursos. Conforme versa o artigo 5ํ, VIII, da Portaria nํ10/2017:

[...] manter pacientes em observação, por até 24 horas, para elucidação diagnóstica ou estabilização clínica, e encaminhar aqueles que não tiveram suas queixas resolvidas com garantia da continuidade do cuidado para internação em serviços hospitalares de retaguarda, por meio da regulação do acesso assistencial. (BRASIL, 2017).

Deste modo, conforme o site do Ministério da Saúde:

A Rede de Atenção às Urgências tem como objetivo reordenar a atenção à saúde em situações de urgência e emergência de forma coordenada entre os diferentes pontos de atenção que a compõe, de forma a melhor organizar a assistência, definindo fluxos e as referências adequadas. [...]. Assim, para que a Rede oferte assistência qualificada aos usuários, 
é necessário que seus componentes atuem de forma integrada, articulada e sinérgica. Sendo indispensável a implementação da qualificação profissional, da informação, do processo de acolhimento e da regulação de acesso a todos os componentes que a constitui. (MINISTÉRIO DA SAÚDE, 2020).

Destaca-se, novamente, a Portaria $\mathrm{n}^{\circ} 10$ de 3 de janeiro de 2017 que "Redefine as diretrizes de modelo assistencial e financiamento de UPA 24h de Pronto Atendimento como Componente da Rede de Atenção às Urgências, no âmbito do Sistema Único de Saúde" e, em seu art. $5^{\circ}$ elenca as atividades que devem ser consideradas para seu efetivo funcionamento. (BRASIL, 2017).

Nessa direção,

[...] A UPA inova ao oferecer estrutura simplificada, com raio-X, eletrocardiografia, pediatria, laboratório de exames e leitos de observação. Nas localidades que contam com UPA, 97\% dos casos são solucionados na própria unidade. Quando o usuário chega às unidades, os médicos prestam socorro, controlam o problema e detalham o diagnóstico. Eles analisam se é necessário encaminhar a um hospital ou mantê-lo em observação por 24 horas. (MINISTÉRIO DO PLANEJAMENTO, 2020).

Há de se considerar ainda, um importante fator que envolve a permanência dos pacientes com relação ao processo final para produção da unidade - o Faturamento, haja visto que a normativa se baseia em apenas um (1) dia, conforme lançamento via sistema SIA/SUS - Boletim de Produtividade Individual- BPA - I: Procedimento: 03.01.06.002-9 - Atendimento de Urgência com observação até 24h em atenção especializada, Procedimento: 03.01.06.009-6 - Atendimento Médico em UPA 24h de Pronto Atendimento, Procedimento: 03.01.06.010-0 - Atendimento Ortopédico com Imobilização Provisória e Procedimento: 03.01.06.011-8 - Acolhimento com Classificação de Risco. Os referidos códigos encontram-se no Art. 40 da Portaria no 10/2017 de 03 de janeiro de 2017 - Ministério da Saúde.

Diante do exposto, o referido estudo reporta a permanência superior a 24 horas em uma Unidade de Pronto Atendimento-UPA24h, Porte III, cidade de Santarém/PA, sob gestão municipal. Atualmente possui uma estrutura física composta por mais de 40 (quarenta) salas que possibilitam o atendimento assistencial, logístico e operacional, 
médicos plantonistas-clínicos gerais e equipe multiprofissional que estão à disposição 24h para melhor atender aos usuários.

A Unidade está localizada na Avenida Curuá-Una, s/n, Bairro Diamantino, e atende pacientes dos bairros Santana, Prainha, Maicá, Mararu, Livramento, São José Operário, Jaderlândia, Cohab, Santíssimo, Santo André e Área Verde, além de outros bairros, zona rural e municípios conforme identificados neste trabalho. A UPA 24h Santarém foi inaugurada em 28 de junho de 2014. (PORTAL G1, 2014).

Para tanto, o fluxo de atendimento aos usuários pode ser por livre demanda, por referência e contrarreferência das Unidades Básicas de Saúde-UBSs ou via Serviço de Atendimento Móvel de Urgência-SAMU, onde o setor de Acolhimento com Classificação de Risco/Triagem, por meio de um profissional de enfermagem (Enfermeiro) irá fazer a anamnese e avaliação da queixa do paciente e, posteriormente correlacionar ao Protocolo de Manchester, que preconiza a identificação do risco por meio de pulseiras, determinada por cores, do mais grave ao menos grave: vermelho, amarelo, verde e azul. Cada cor de classificação tem um tempo específico máximo para o atendimento médico, conforme Portal da Enfermagem (2020). Aos pacientes com procedência via SAMU há outro fluxo de atendimento, priorizando primeiro o atendimento médico.

Nesse contexto,

A Unidade de Pronto Atendimento (UPA 24h) faz parte da Rede de Atenção às Urgências. $O$ objetivo é concentrar os atendimentos de saúde de complexidade intermediária, compondo uma rede organizada em conjunto com a atenção básica, atenção hospitalar, atenção domiciliar e o Serviço de Atendimento Móvel de Urgência - SAMU 192. (BRASIL, 2020).

O município de Santarém está situado no oeste do Estado do Pará, às margens do Rio Tapajós. Conforme Santarém (2020), é uma cidade que reúne até hoje os descendentes indígenas, portugueses, estadunidenses e nordestinos, que com muito trabalho promovem o crescimento da nossa sociedade. Tendo sua fundação em 22/06/1661, ou seja, acaba de completar 359 anos. 
É considerado um centro de referência (cidade polo) tanto no cenário econômico, social e da saúde, sendo este último porta de entrada regulada ou de livre demanda à pacientes de média e alta complexidade para todos os municípios da região do oeste do Pará, compreendendo uma população com cerca de 1.000.000 de habitantes. Todavia, de acordo IBGE (2020) a população estimada do município de Santarém para o ano de 2019 é de 304.589 pessoas.

Santarém pertence a 9a Regional de Saúde da Secretaria de Saúde do Estado do Pará-SESPA, juntamente com outros 19 municípios. Dessa forma, de acordo com SESPA (2020) "As Regionais de Saúde são as unidades administrativas da SESPA distribuídas em todo o território paraense visando descentralização de serviços e redução das barreiras geográficas para melhor atender ao cidadão".

\section{DESENVOLVIMENTO}

O presente artigo consiste em uma pesquisa descritiva documental quantitativa e qualitativa, cujo produto é uma pesquisa aplicada na Unidade de Pronto Atendimento 24h de Santarém/PA.

Como o intuito de identificar os fatores que ocasionaram a observação de pacientes superior a 24h na UPA de Santarém, através de um diagnóstico situacional contribuindo para uma análise da efetividade da unidade, foram definidas as seguintes ações: A) Dimensionar o tempo de permanência dos pacientes das Salas de Observação Adulta, Sala de Observação Pediátrica e Sala de Urgência/Sala Vermelha; B) Mapear os diagnósticos dos pacientes que ficaram em observação por mais de 24h na UPA de Santarém; C) Identificar os bairros e municípios dos pacientes estudados; D) Conhecer suas características demográficas de idade e sexo; E) Realizar levantamento da rede de saúde pública de Santarém e sua abrangência regional.

O primeiro instrumento de trabalho foi o sistema de controle manual denominado censo, utilizado pela equipe de enfermagem para os pacientes assistidos nas Salas de Observação Adulto, Observação Pediátrica e Sala de Urgência/Vermelha durante 
os meses de junho, julho e agosto de 2019 , onde, após plotagem em planilha excel e análise, demonstravam um número significativo de pacientes em observação por período superior a 24 horas.

Partiu-se então, para uma pesquisa mais criteriosa sobre o tempo médio de permanência dos usuários das unidades supracitadas e problema de saúde incidente (diagnóstico médico). Desta forma, foi realizada pesquisa junto ao SAME-Serviço de Arquivo Médico e Estatístico da unidade para a separação dos prontuários contidos na planilha elaborada pós censo com intenção de identificar a data do atendimento inicial, a idade, o problema de saúde incidente/diagnóstico, o bairro, a data e o motivo da alta do paciente.

Com base no diagnóstico identificado no prontuário do paciente, foi realizada pesquisa no site DATASUS CID-10 para que se pudesse correlacionar a categoria da doença e se trabalhar com uma informação padronizada, uma vez que por se tratar de unidade de pronto atendimento, não há formulário de Autorização para Internação Hospitalar$\mathrm{AlH}$, bem como o médico não descreve a categoria CID da doença no prontuário do paciente.

Cabe mencionar que,

A CID-10 foi conceituada para padronizar e catalogar as doenças e problemas relacionados à saúde, tendo como referência a Nomenclatura Internacional de Doenças, estabelecida pela Organização Mundial de Saúde. Com base no compromisso assumido pelo Governo Brasileiro, a organização dos arquivos em meio magnético e sua implementação para disseminação eletrônica foi efetuada pelo DATASUS, possibilitando, assim, a implantação em todo o território nacional, nos registros de Morbidade Hospitalar e Ambulatorial, compatibilizando estes registros entre todos os sistemas que lidam com morbidade. Benefícios: Permite que programas e sistemas possam referenciar, de forma padronizada, as classificações; auxilia a busca de informação diagnóstica para finalidades gerais. (MINISTÉRIO DA SAÚDE, 2020).

Após coleta manual e tabulação dos dados foram construídos vários indicadores e, elucidados por meio dos gráficos com dados fidedignos da amostra em estudada. 
Importante destacar que no período de realização deste estudo o sistema de prontuário eletrônico do paciente-PEP encontrava-se em fase de implantação, onde num futuro próximo pretende-se obter vários benefícios que agregará valores na análise e segurança das informações, integrando o cuidado ao paciente.

Diante das características regionais e geográficas, despertou-se, ainda, o interesse em conhecer as distâncias dos 19 municípios circunvizinhos, considerados referência em relação a Santarém, já que é considerada cidade polo, sendo o deslocamento por via terrestre e fluvial.

Tabela 1. Distância entre os Municípios

\begin{tabular}{|c|c|c|}
\hline $\begin{array}{lr}9^{a} \quad \text { REGIONAL } & \text { DE } \\
\text { SAÚDE } & - \\
\text { MUNICÍPIOS } & \end{array}$ & DISTÂNCIA DE SANTARÉM & $\begin{array}{l}\text { FORMA DE } \\
\text { DESLOCAMENTO }\end{array}$ \\
\hline Alenquer & $\begin{array}{l}\text { Não foi possível calcular a rota } \\
\text { terrestre }\end{array}$ & Fluvial \\
\hline Almerim & $\begin{array}{l}\text { Não foi possível calcular a rota } \\
\text { terrestre }\end{array}$ & Fluvial \\
\hline Aveiro & $\begin{array}{l}\text { Não foi possível calcular a rota } \\
\text { terrestre }\end{array}$ & Fluvial \\
\hline Belterra & $49,3 \mathrm{~km}$ & Terrestre \\
\hline Curuá & $\begin{array}{l}\text { Não foi possível calcular a rota } \\
\text { terrestre }\end{array}$ & Fluvial \\
\hline Faro & $\begin{array}{l}\text { Não foi possível calcular a rota } \\
\text { terrestre }\end{array}$ & Fluvial \\
\hline Itaituba & $369 \mathrm{~km}$ & Terrestre + fluvial \\
\hline Jacareacanga & $759 \mathrm{~km}$ & Terrestre + fluvial \\
\hline Juruti & $207 \mathrm{~km}$ & Terrestre + fluvial \\
\hline Mojuí dos Campos & $33,3 \mathrm{~km}$ & Terrestre \\
\hline
\end{tabular}




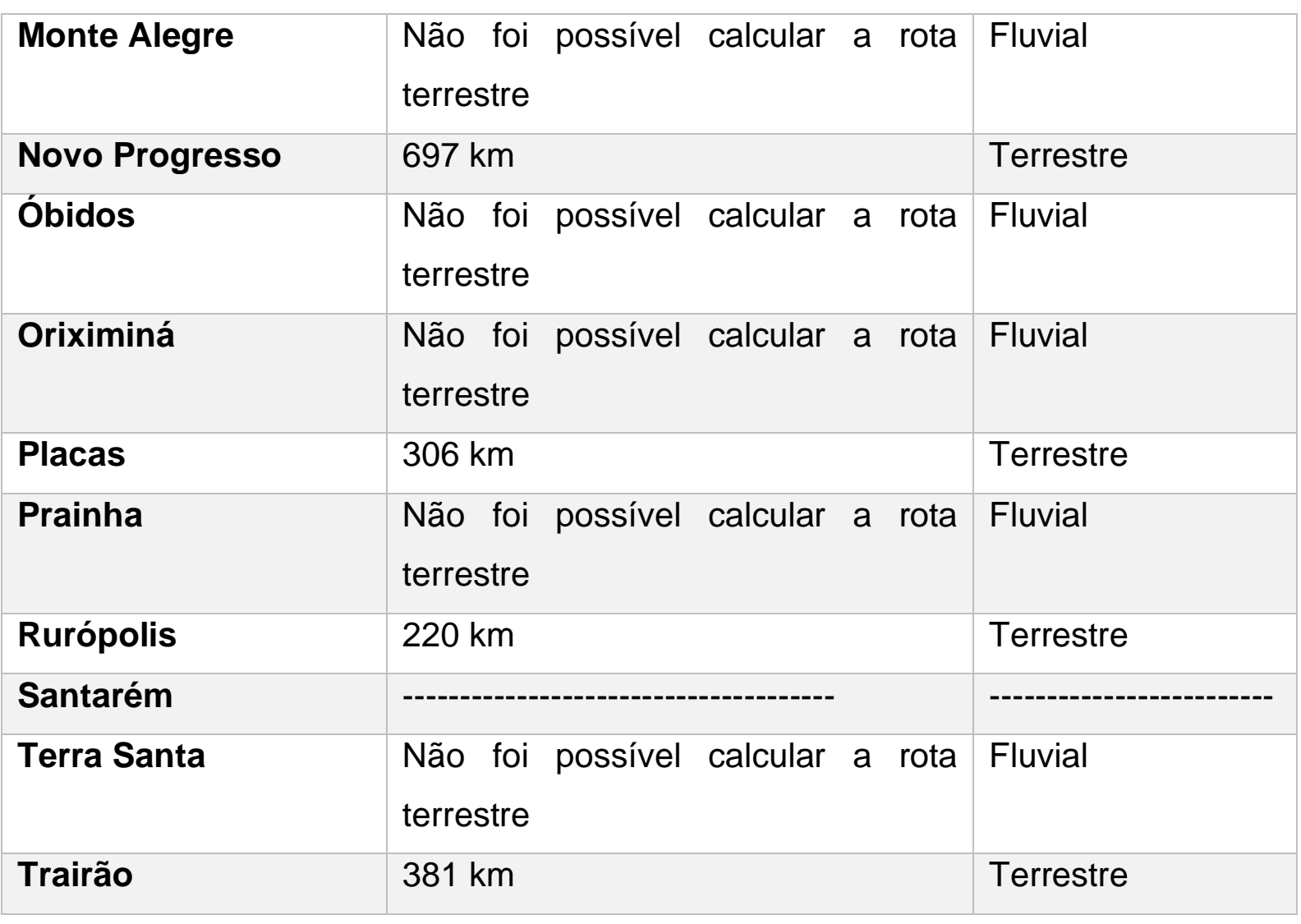

Fonte: Adaptado de SESPA e Google Maps (2019).

Cabe destacar que a UPA 24h é um equipamento de saúde pública, que por sua vez preconiza os princípios do Sistema Único de Saúde-SUS, onde a equidade e a universalidade foram evidenciados por meio dos atendimentos a pacientes advindos de regiões geograficamente fora da área de cobertura da unidade de pronto atendimento, garantindo a integralidade do cuidado ao usuário.

Visando conhecer a rede assistencial à saúde local, foi realizado um levantamento da rede de saúde no município de Santarém, bem como oferta de leitos hospitalares conforme descrito a seguir: 
Tabela 2. Tipos de Estabelecimentos de Saúde de Santarém/PA no CNES - Cadastro Nacional de Estabelecimentos de Saúde

\begin{tabular}{|l|c|}
\hline \multicolumn{1}{|c|}{ DESCRIÇÃO } & TOTAL \\
\hline POSTO DE SAÚDE & 06 \\
\hline CENTRO DE SAÚDE/UNIDADE BÁSICA & 66 \\
\hline HOSPITAL GERAL & 05 \\
\hline HOSPITAL ESPECIALIZADO & 01 \\
\hline $\begin{array}{l}\text { UNIDADE MÓVEL DE NÍVEL PRÉ-HOSPITALAR NA ÁREA DE } \\
\text { URGÊNCIA }\end{array}$ & 04 \\
\hline UNIDADE DE PRONTO ATENDIMENTO & 01 \\
\hline \multicolumn{1}{|c|}{ DESCRIÇ̃̃O } & TOTAL \\
\hline LEITOS SUS & 472 \\
\hline LEITOS NÃO SUS & 81 \\
\hline TOTAL GERAL & 508 \\
\hline
\end{tabular}

Fonte: Adaptado do Ministério da Saúde (2019).

\section{RESULTADOS E DISCUSSÕES}

O problema identificado no presente estudo de caso foi sobre a existência de pacientes com permanência superior a 24 horas na UPA de Santarém nas salas de Observação Adulto, Sala de Urgência/Vermelha e Sala de Observação Pediátrica, cujo período analisado foram os meses de junho, julho e agosto de 2019.

O tempo de permanência dos pacientes nas Salas de Observação Adulto, Observação Pediátrica e Sala de Urgência/Vermelha no período supracitado foi a média de 3,16 dias, com base na amostra de 289 pacientes.

Outro aspecto relevante apontado nas pesquisas foi o número de dias absolutos de permanência dos pacientes, considerando um parâmetro maior e outro menor:

- Sala de Observação Adulto: 11 dias / 2 dias; 
- Sala de Observação Pediátrica: 5 dias / 2 dias;

- Sala de Urgência/Vermelha: 12 dias / 2 dias.

As atividades que permearam este estudo buscaram traçar uma visão holística de cenário dos atendimentos na UPA 24h considerando a problemática de manter pacientes em observação em período superior aos princípios normativos que a regulamenta, em paralelo a uma análise das ofertas de serviços de saúde em Santarém, sendo uma cidade referência para outros municípios circunvizinhos.

A insuficiência de leitos de retaguarda no Hospital Municipal de Santarém-HMS, quer seja na unidade de terapia intensiva-UTI ou nas enfermarias de clínica médica resultara na inviabilização imediata de alguns pedidos de regulação para transferência do paciente pela equipe médica da UPA ao Núcleo Interno de Regulação-NIR do HMS, transcorrendo na permanência do paciente/internação na unidade até a efetiva alta, porém, nem sempre havendo pedido de transferência.

A realização das atividades propostas neste estudo de caso e o diálogo com a equipe de profissionais da UPA 24h reportaram algumas não conformidades no tempo de solicitação versus realização de exames de imagem, bem como o tempo de coleta laboratorial versus resultado, fatores estes avaliados numa análise global para todos os pacientes, não sendo mensurado e/ou correlacionado com o tempo de permanência dos pacientes deste trabalho devido não haver controle via sistema. $\mathrm{A}$ priori, os controles manuais não ofereceram constância nos registros. 
Gráfico 1. Tempo de permanência

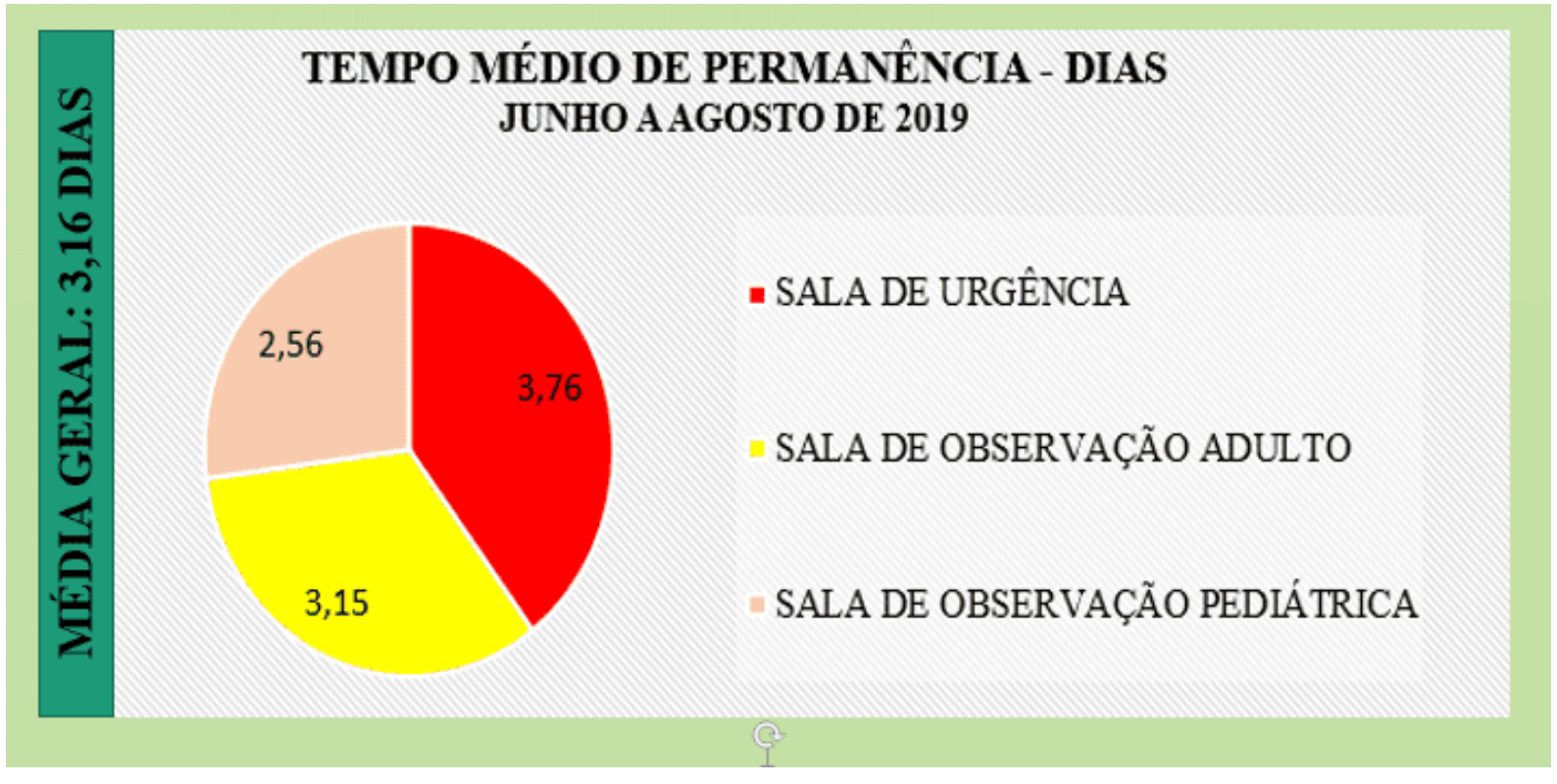

Fonte: Adaptado de UPA Santarém (2019).

Para se obter os resultados do gráfico 1 foram realizadas as médias aritméticas dos meses de junho, julho e agosto de 2019 de cada sala, com base no total de dias que os pacientes estiveram em observação/internação divididos pelo total de pacientes. Sendo estas médias superior a legislação UPA preconizada por meio da Portaria do Ministério da Saúde - GM no 10 de 03 de janeiro de 2017, Art. 5, VIII: [...] "manter pacientes em observação, por até 24 horas, para elucidação diagnóstica ou estabilização clínica [...]”. (BRASIL, 2017).

A auditoria do Tribunal de Contas da União (2012), por meio de um estudo de caso realizado em 4 (quatro) unidades da Federação, apontou os seguintes indicadores com relação a "Frequência com que os pacientes permanecem por mais de 24 horas nas UPAs", respondidas pelos Coordenadores via questionário, sendo: Muitas vezes (54\%), Poucas vezes (34\%), Sempre (9\%) e Nunca (3\%).

Conforme Vieira (2015) em estudo de caso realizado em uma Unidade de Pronto Atendimento de São José dos Pinhais/PR com base numa amostra de 642 pacientes no período de 01/01/2014 a 31/08/2014, exceto menores de 13 anos, evidencia-se 
que $59 \%$ permaneceram por mais de 24 horas a 5 dias, $20 \% 6$ a 10 dias e $21 \% 11$ a 30 dias.

Gráfico 2. Comparativo de permanência

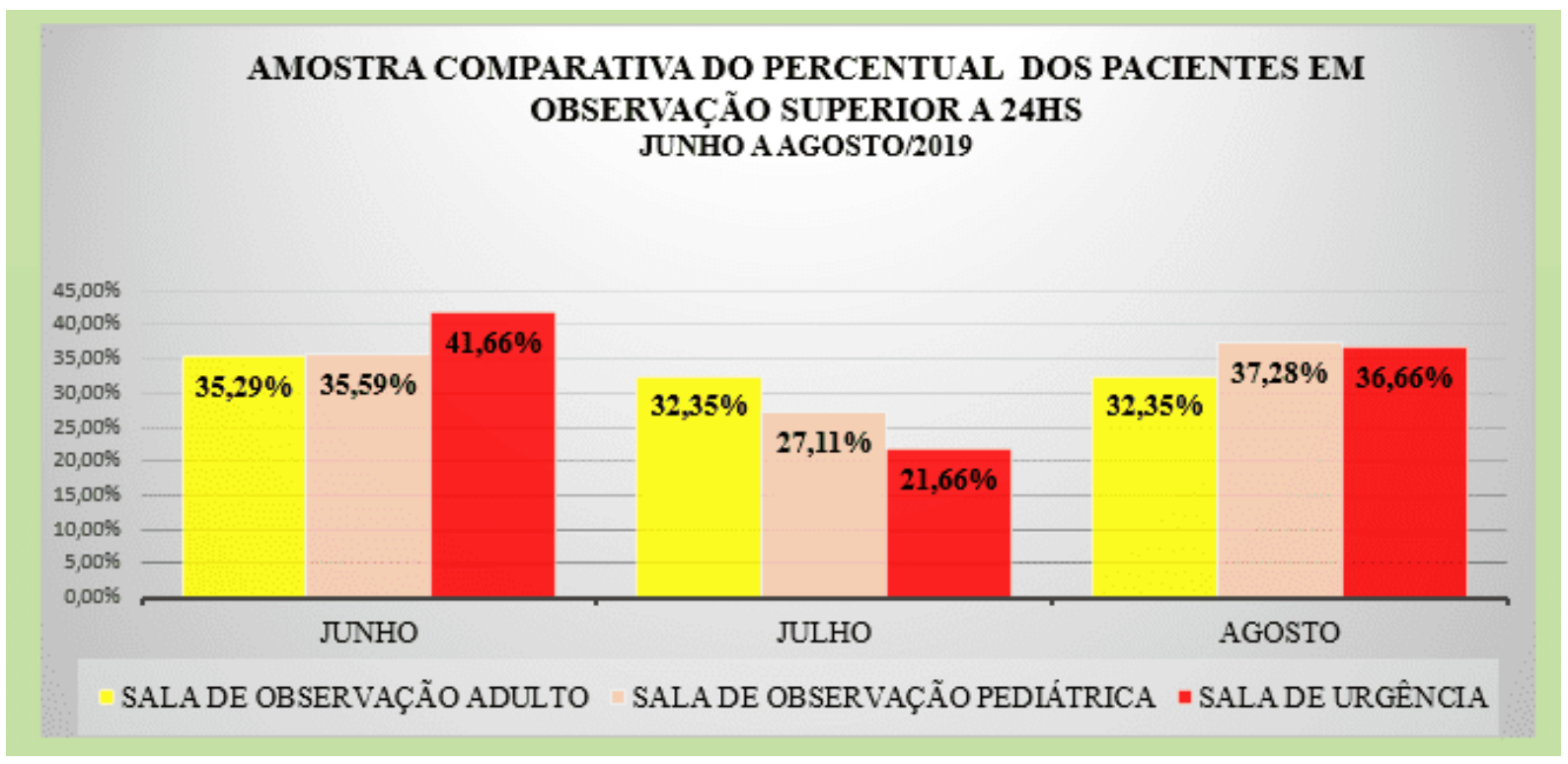

Fonte: Adaptado de UPA Santarém (2019).

Os dados do gráfico 2 são resultantes do percentual representativo do total de pacientes de cada mês estudado comparado ao total de paciente de cada Sala de Observação dentro do referido mês.

Todavia, cabe ainda apresentar os dados correspondentes a cada Sala de Observação na correlação com o total da amostra de pacientes versus o total de dias de permanência dos mesmos: a Sala de Observação Adulto apresentou 170 pacientes/536 dias, a Sala de Observação Pediátrica apresentou 59 pacientes/151 dias e a Sala de Urgência apresentou 60 pacientes/228 dias.

Os dados supramencionados evidenciam uma preocupante realidade quanto a nãoconformidade do objetivo de estabilização do paciente na UPA 24h, pois a mesma está sendo utilizada como unidade clínica de internação e tratamento para diversas especialidades médicas, não apenas para casos de urgência e emergência. Por exemplo, se considerarmos que cada paciente deveria permanecer na unidade por 
até $24 \mathrm{~h}$ (1 dia) temos os seguintes dados oriundos da pesquisa: a Sala de Observação Adulto representou o excedente de 366 dias. Nessa mesma linha de raciocínio a Sala de Observação Pediátrica o excedente de 92 dias e, a Sala de Urgência 168 dias. Totalizando 289 pacientes em observação por 915 dias, ou seja, excedente de 626 dias ou pacientes que poderiam ter sido assistidos. Não cabendo aqui adentrar na seara financeira.

Há de se considerar que as Redes de Atenção à Saúde-RAS, são arranjos organizativos de uma política pública de saúde que através de uma estrutura de serviços de saúde buscam a integralidade do cuidado aos cidadãos nos níveis de atenção considerados primário, secundário e terciário. Portanto, a UPA 24h se enquadra no nível secundário, sendo um componente da Rede de Atenção às Urgências e Emergências-RUE, articulando-se com outras estruturas de uma rede assistencial organizada de serviços em saúde.

Observa-se que outro importante instrumento legal, também a nível federal, corrobora com esta política pública de saúde. A Resolução CFM № 2.079/14 dispõe sobre a normatização do funcionamento das Unidades de Pronto Atendimento (UPA) 24h e congêneres, bem como do dimensionamento da equipe médica e do sistema de trabalho nessas unidades, mantendo em seu $12^{\circ}$ artigo o estabelecimento da permanência do paciente para elucidação diagnóstica e tratamento de $24 \mathrm{~h}$ e, em seu $15^{\circ}$ artigo veda a internação de pacientes.

Na sequência, outro indicador denominado "Motivo da Alta" está descrito em 6 (seis) variantes, quais sejam: Residência, Evasão, Hospital Municipal, Hospital Regional, Interna e Óbito. Para melhor elucidar os dados, foram separadas as 3 salas de observação do presente estudo (Sala de Observação Adulto, Observação Pediátrica e Sala de Urgência), apresentando em percentuais os referenciais do tempo de permanência.

Cabe esclarecer a categoria intitulada "Interna", pois em alguns casos o paciente fora transferido de uma sala para outra (ora Sala de Observação Adulta para a Sala de 
Urgência/Sala Vermelha ora da Sala de Urgência/Sala Vermelha para a Sala de Observação Adulta) conforme identificado na evolução do prontuário.

Gráfico 3. Motivo da alta

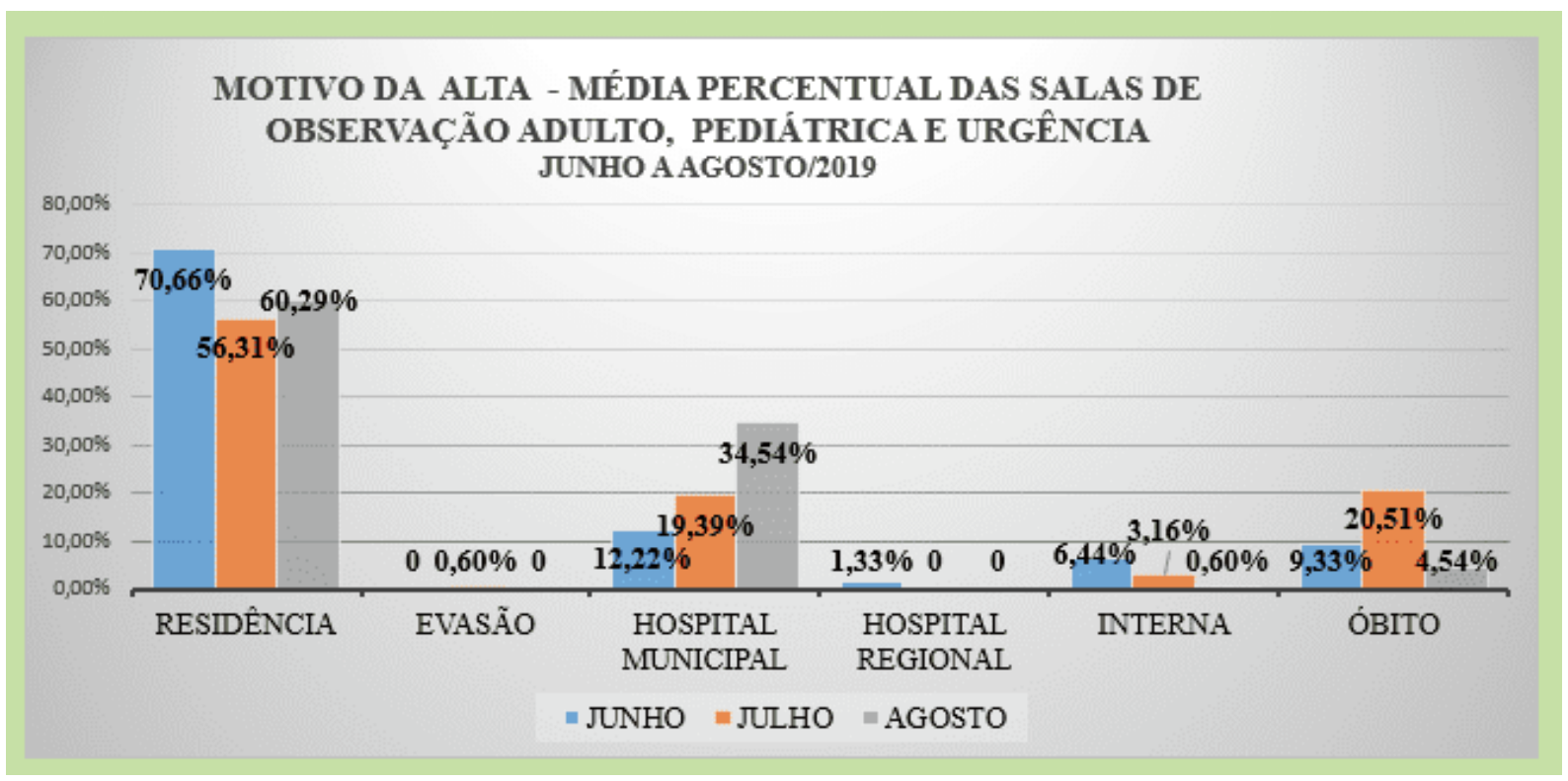

Fonte: Adaptado de UPA Santarém (2019).

O referido gráfico apresenta a média aritmética das 3 Salas consolidando os percentuais das variáveis, visando um comparativo entre os Motivos da Alta/Evolução dos pacientes na unidade de saúde no período estudado, destacando-se maior efetividade da alta por motivo de transferência do paciente para o Hospital Municipal.

Outro parâmetro importante a ser apresentado é o percentual do motivo da alta para o Hospital Municipal-HMS no mês de agosto na Sala de Urgência/Sala Vermelha, refletindo no percentual de $72,72 \%$, quando analisado fora da média aritmética.

Mesmo estando em não conformidade com a observação em período de até 24 horas, o indicador supramencionado está em consonância com as normativas da Portaria 10/2017, Art. $5^{\circ}$ item VIII conforme mencionado anteriormente, haja visto que a UPA foi concebida para servir de porta de entrada aos atendimentos de urgência e emergência e, conforme o caso, o pode ter sua resolutividade na unidade, estabilizado e/ou encaminhado para um hospital, ou ainda, ser redirecionado a uma UBS. 
De acordo com o exposto,

Em 2003, foi inaugurada a Política Nacional de Atenção às Urgências (PNAU), cujo ineditismo repousava no olhar ampliado proposto para a questão. Essa política deu especial atenção à assistência pré-hospitalar e enfatizou a compreensão de que a atenção às urgências não está restrita ao hospital. Para isso, retomou a proposta de constituição de redes locorregionais de atenção às urgências com um componente préhospitalar fixo, composto tanto pela atenção básica $(\mathrm{AB})$ como por unidades de pronto-atendimento não hospitalares, que constituiriam retaguarda para a primeira. Documentos subsequentes instruíram implantação, financiamento e expansão desse componente, que viria a ser popularizado como Unidades de Pronto Atendimento 24h (UPA). (KONDER E O'DWYER, 2016, p. 880).

A Tabela 3 consolida a classificação das categorias de diagnóstico dos pacientes estudados e, posteriormente associadas ao CID-10 - Classificação Estatística Internacional de Doenças e Problemas Relacionados à Saúde.

Tabela 3. Categorias CID-10

DOENÇAS INFECCIOSAS E PARASITÁRIAS (A00-B99)

DOENÇAS ENDÓCRINAS, NUTRICIONAIS E METABÓLICAS (E00-

E90)

DOENÇAS DO SISTEMA NERVOSO (G00-G99)

DOENÇAS DO APARELHO CIRCULATÓRIO (100-199)

DOENÇAS DO APARELHO DIGESTIVO (K00-K93)

DOENÇAS DO APARELHO RESPIRATÓRIO (J00-J99)

DOENÇAS DA PELE E DO TECIDO SUBCUTÂNEO (L00-L99)

DOENÇAS DO APARELHO GENITURINÁRIO (N00-N99)

Fonte: Adaptado do Ministério da Saúde (2019). 
Gráfico 4. CID - Classificação Internacional de Diagnóstico dos pacientes do estudo de caso

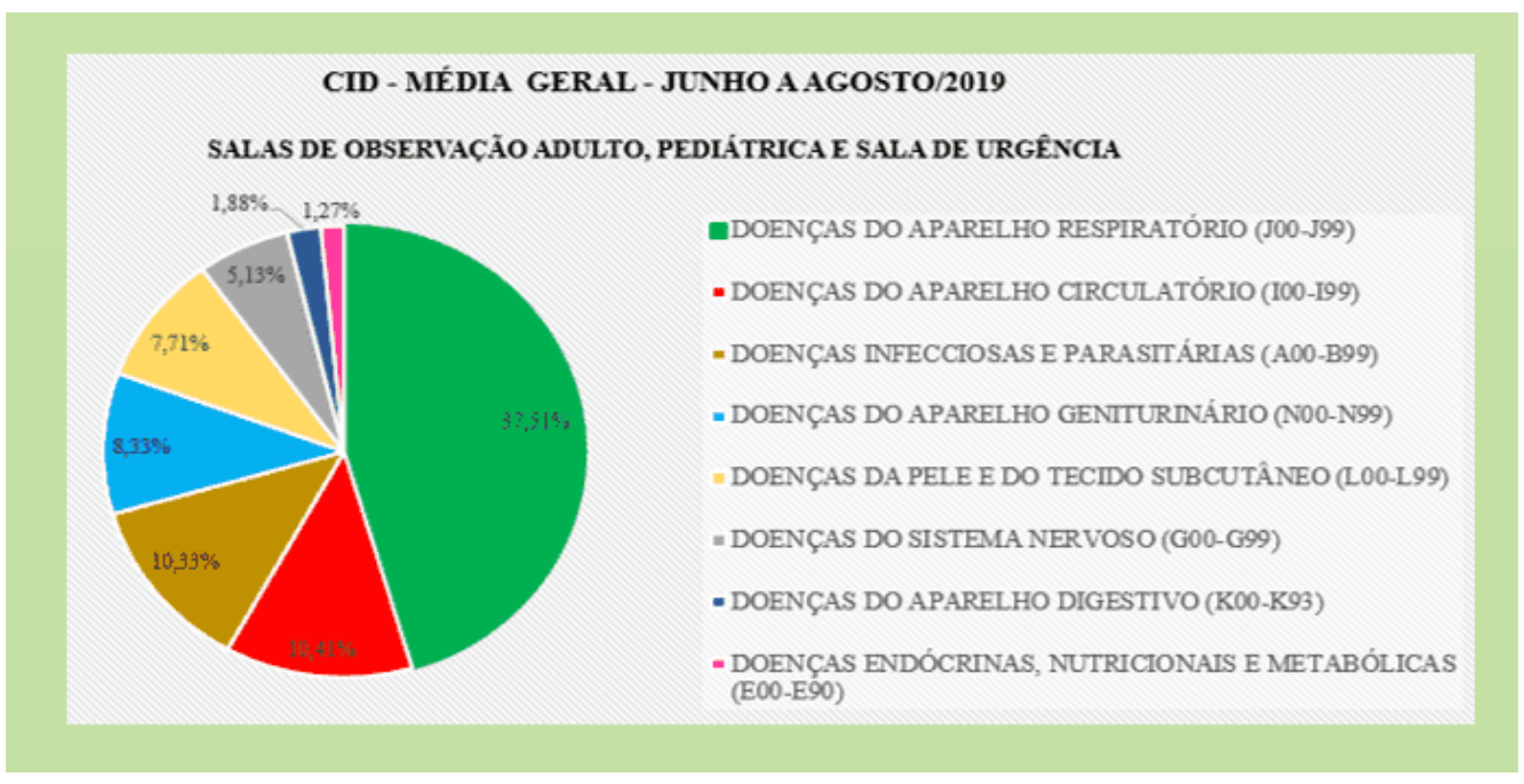

Fonte: Adaptado de UPA Santarém (2019).

O gráfico acima demonstra a média geral em percentual da CID-10 categorizadas durante o período deste estudo, onde as três maiores classificações foram: Doenças do Aparelho Respiratório (37,51\%), Doenças do Aparelho Circulatório $(10,41 \%)$ e as Doenças Infecciosas e Parasitárias (10,33\%). Todavia, conforme a Tabela 4, foram identificados diagnósticos associados.

Especificamente em relação as Doenças do Aparelho Respiratório, destacamos que a Sala de Observação Pediátrica evidenciou os seguintes dados percentuais: $85,51 \%$ em junho/2019, 56,25\% em julho/2019 e 50,0\% em agosto/2019. Sendo estes os maiores percentuais comparados com as demais salas de observação. 
Tabela 4: Categorias da CID Associadas

\begin{tabular}{|c|c|}
\hline CATEGORIA DA CID-10 & PERCENTUAL \\
\hline DOENÇAS DO APARELHO CIRCULATÓRIO (I00-I99) + RESPIRATÓRIO (J00-J99) & $4,49 \%$ \\
\hline DOENÇAS DO SISTEMA NERVOSO (G00-G99) + CIRCULATÓRIO (I00-I99) & $1,73 \%$ \\
\hline DOENÇAS INFECCIOSAS E PARASITÁRIAS + DOENÇAS DO SISTEMA NERVOSO (G00-G99) & $1,73 \%$ \\
\hline $\begin{array}{l}\text { SINAIS, SINTOMAS E ACHADOS ANORMAIS DE EXAMES CLÍNICO ... (R00-R99) + CIRCULATÓRIO } \\
\text { (I00-I99) }\end{array}$ & $1,38 \%$ \\
\hline $\begin{array}{l}\text { DOENÇA DA PELE E TECIDO SUBCUTANEO (L00-L99) + DOENÇAS ENDÓCRINAS, NUTRICIONAIS } \\
\text { E METABÓLICAS (E00-E90) }\end{array}$ & $1,03 \%$ \\
\hline $\begin{array}{l}\text { DOENÇAS INFECCIOSAS E PARASITÁRIAS (A00-B99) + DOENÇAS DO SISTEMA RESPIRATÓRIO } \\
\text { (J00-J99) }\end{array}$ & $1,03 \%$ \\
\hline $\begin{array}{l}\text { SINAIS, SINTOMAS E ACHADOS ANORMAIS DE EXAMES CLÍNICOS E DE LABORATORIO, NÃO } \\
\text { CLASSIFICADOS EM OUTRA PARTE (R00-R99) }\end{array}$ & $1,03 \%$ \\
\hline $\begin{array}{l}\text { DOENÇAS DO APARELHO GENITURINÁRIO (N00-N99) + CIRCULATÓRIO (I00-I99) + RESPIRATÓRIO } \\
\text { (J00-J99) }\end{array}$ & $1,03 \%$ \\
\hline DOENÇAS DO APARELHO GENITURINÁRIO (N00-N99) + CIRCULATÓRIO (I00-I99) & $0,69 \%$ \\
\hline $\begin{array}{l}\text { DOENÇAS INFECCIOSAS E PARASITÁRIAS (A00-B99) + DOENÇAS ENDÓCRINAS, NUTRICIONAIS E } \\
\text { METABÓLICAS (E00-E90) }\end{array}$ & $0,34 \%$ \\
\hline $\begin{array}{l}\text { DOENÇA DO APARELHO CIRCULATÓRIO (I00-I99)+ DOENÇAS INFECCIOSAS E PARASITARIAS } \\
\text { (A00-B99) }\end{array}$ & $0,34 \%$ \\
\hline
\end{tabular}

Fonte: Adaptado de UPA Santarém (2019).

A Secretaria de Vigilância em Saúde do Ministério da Saúde (2020) reporta informações que conforme avaliação do perfil epidemiológico e demográfico brasileiro, há evidências que os principais problemas que acometem os usuários de urgência e emergência estão voltados a alta morbimortalidade de doenças do aparelho circulatório (Infarto Agudo do Miocárdio e Acidente Vascular Cerebral) e violências e acidentes de trânsito.

Consoante aos diagnósticos identificados nos prontuários dos pacientes da UPA 24h e, traduzidas no gráfico acima, trazemos à reflexão o ponto de vista de Mendes (2011):

[...] existem evidências de que a melhoria da AS é que permite alcançar esses objetivos e atender, com efetividade, os portadores de condições de urgências menores (azuis e verdes), a grande maioria de pessoas usuárias em situação de urgência. A retenção dessas pessoas de menores riscos nas unidades de APS é uma pré-condição para a organização do atendimento de urgência e emergência de níveis 
secundário e terciário. [...] Ainda que sejam necessárias UPAs, elas não contribuirão para a melhoria da atenção à saúde no SUS se não estiverem integradas em RASs e se, paralelamente, não se organizar a atenção às condições crônicas, também, em redes, mas com uma alta prioridade para a melhoria da qualidade da APS. (MENDES, 2011, p.310)

Em pesquisa ampliada no Sistema de Informações Hospitalares do SUS (SIH-SUS) MORBIDADE HOSPITALAR DO SUS POR LOCAL DE INTERNAÇÃO, identificamos as seguintes informações relacionadas aos 3 primeiros indicadores do gráfico $4-$ CID10, a seguir:

Tabela 5. Categorias da CID-10 conforme Morbidade Hospitalar do SUS por Local de Internação

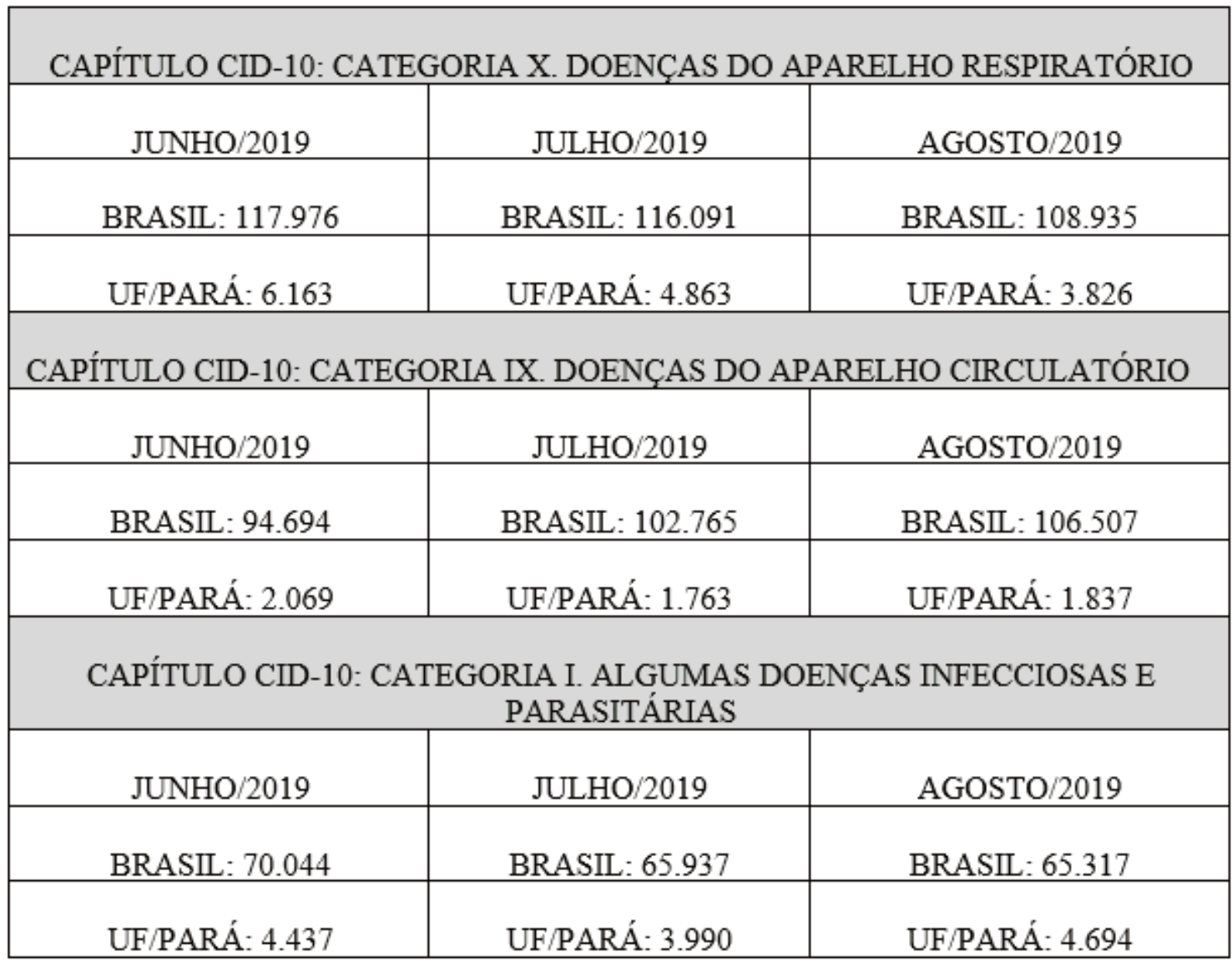

Fonte: Adaptado de DATASUS (2020). 
Quanto às análises demográficas dos pacientes, foi possível conhecer os seguintes resultados:

Gráfico 5. Sexo dos pacientes

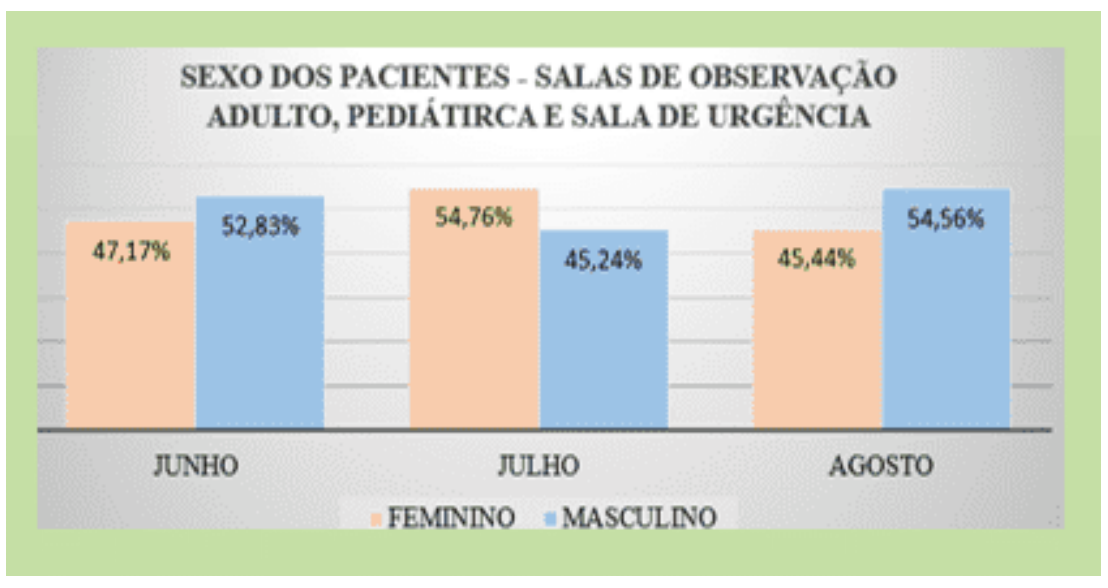

Fonte: Adaptado de UPA Santarém (2019).

A média aritmética representa o percentual de $50,88 \%$ de pacientes do sexo masculino e $49,12 \%$ do sexo feminino.

Gráfico 6. Bairros de maior incidência

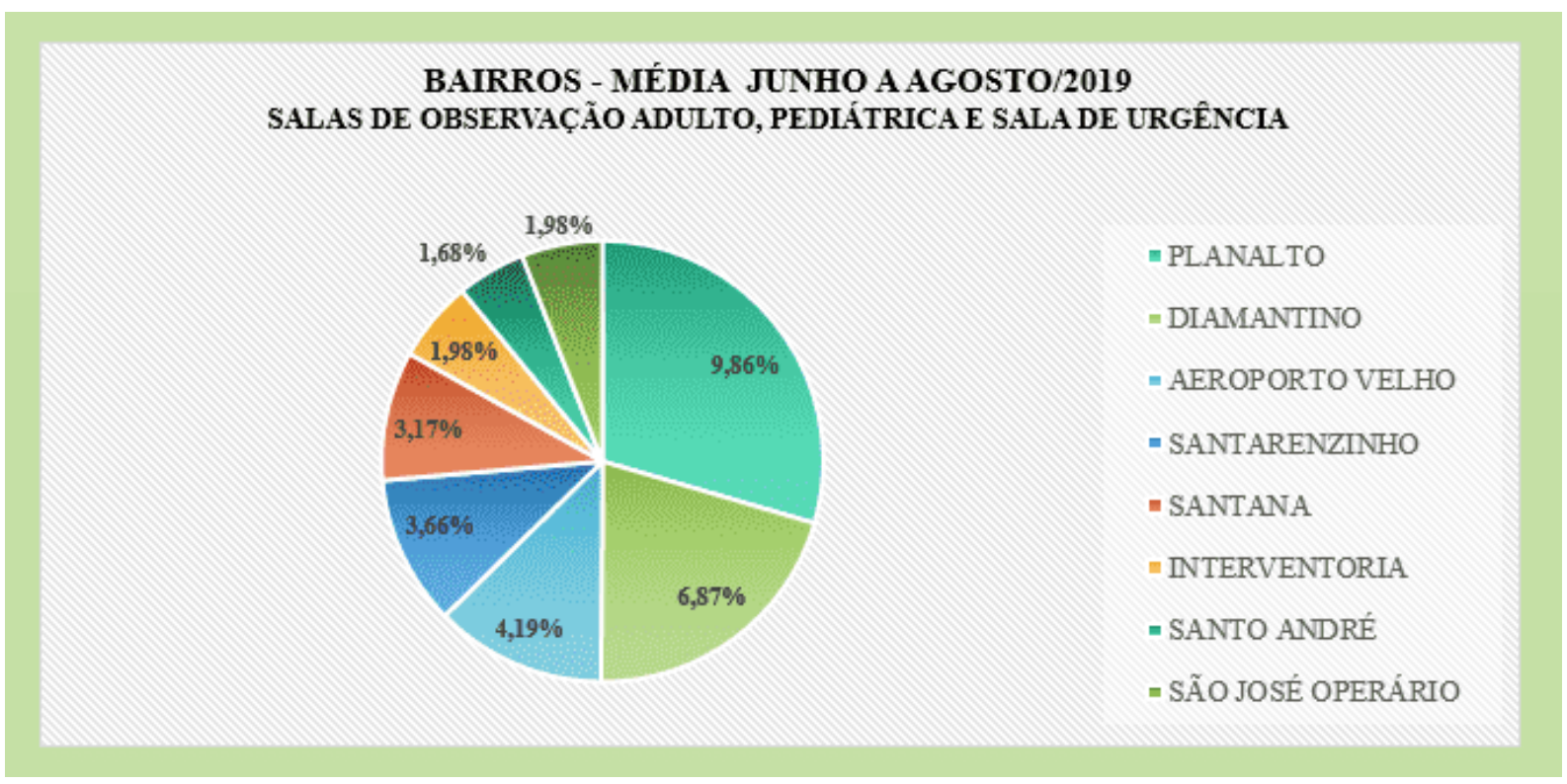

Fonte: Adaptado de UPA Santarém (2019). 
A gráfico acima apresenta a relação dos Bairros dos pacientes que permanecerem em observação/internação no período superior a $24 \mathrm{~h}$ nos meses de junho, julho e agosto de 2019.

Buscou-se comparar os bairros que tiveram maior evidência de atendimentos no período de junho a agosto/2019 chegando a uma média percentual.

Gráfico 8. Faixa etária dos pacientes (anos)

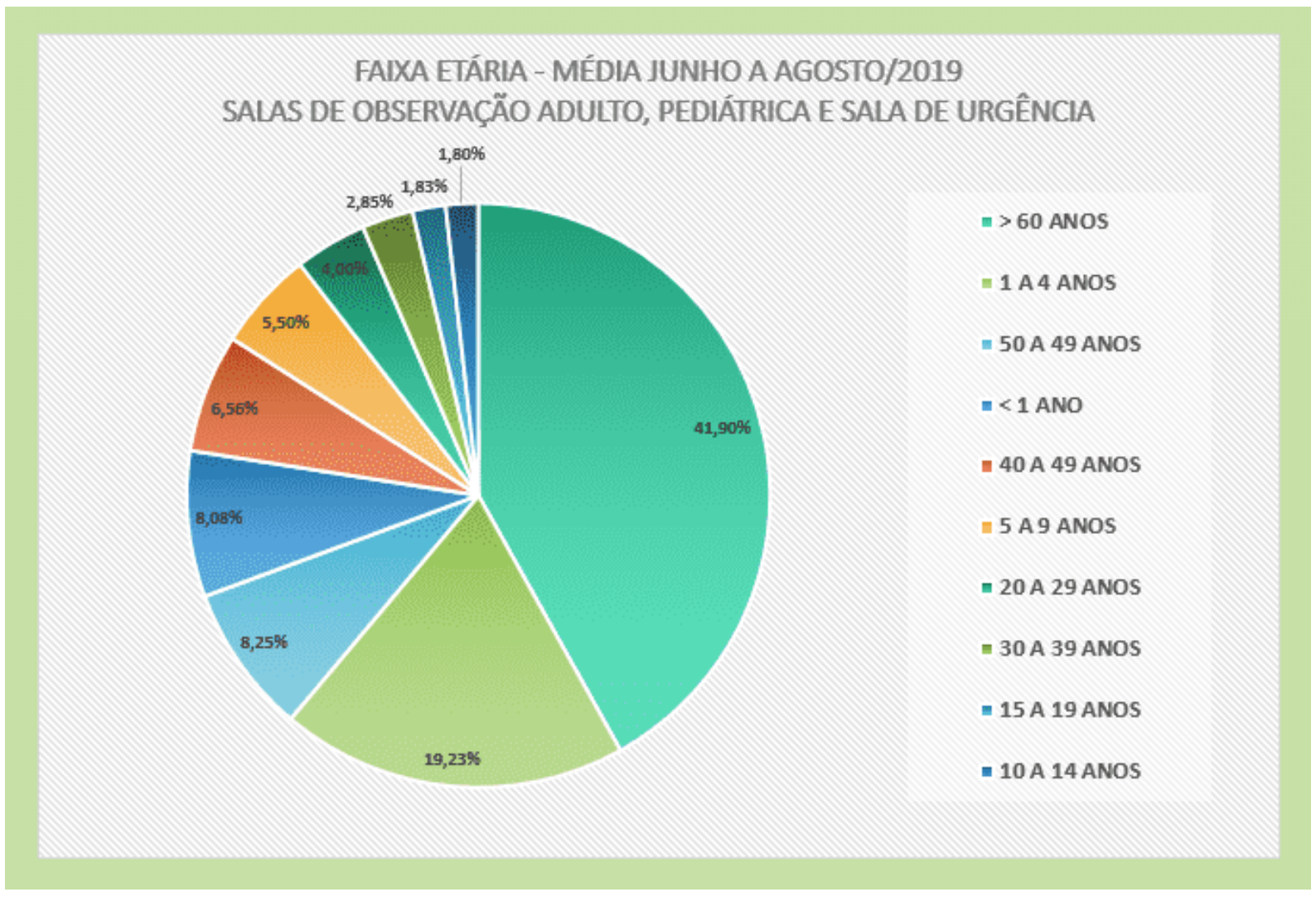

Fonte: Adaptado de UPA Santarém (2019).

Quando analisamos a faixa etária dos pacientes, a média aritmética das 3 Salas de Observação no período deste estudo de caso demonstra o percentual de $41,9 \%$ de pacientes com idade acima dos 60 anos, sendo este o maior dentre as demais faixas etárias. O menor percentual foi para a faixa etária de 10 a 14 anos que corresponde a $1,8 \%$ dentro da amostragem. 
Entretanto, quando avaliamos em separado, destacamos as seguintes médias percentuais dos meses de junho a agosto de 2019: Sala de Urgência (69,80\% para a faixa etária de pacientes acima de 60 anos), Sala de Observação Pediátrica (57,7\% para a faixa etária de 1 a 4 anos) e Sala de Observação Adulto (55,90\% para a faixa etária de pacientes acima de 60 anos).

\section{CONSIDERAÇÕES FINAIS}

Como parte integrante de um grande e importante sistema de rede da saúde pública, as Unidades de Pronto Atendimento se consolidaram à luz de uma estrutura técnica e operacional capaz de ofertar aos cidadãos atendimentos de baixa e média complexidade em consonância com os princípios de universalidade, equidade e integralidade do Sistema Único de Saúde-SUS. Cujo principal objetivo é salvar vidas, além de promover o bem-estar por meio do cuidado e humanização de uma equipe multiprofissional. As equipes atuam $24 \mathrm{hr}$ por dia, durante 7 (sete) dias da semana.

Diante da consolidação dos resultados apresentados por meio da execução das ações propostas neste estudo, acredita-se que o houve êxito em sua realização. Principalmente no que diz respeito ao objetivo intrínseco do aprimoramento e evolução educacional na área.

Foi possível constatar que algumas premissas do componente da Unidade de Pronto Atendimento 24h dentro do componente da Rede de Atenção às Urgências e Emergências do município de Santarém estão sendo efetivadas. Onde evidenciou-se fluxos pertinentes de uma rede organizada desde o acolhimento por meio da classificação de risco, atendimento referenciado e/ou contrarreferenciado, bem como encaminhados à unidade pelo SAMU. Porém, a continuidade do cuidado nos diferentes níveis de atenção dos pontos da RAS não ocorreu de forma eficaz temporalmente conforme preconiza a Portaria ํㅜ10/2017. Foi possível identificar a necessidade de integração sistêmica junto aos demais equipamentos de saúde pública para maior resolutividade do Sistema Único de Saúde-SUS. 
Essas informações levaram aos seguintes questionamentos e reflexões durante a construção da pesquisa, sendo necessário ampliação da mesma em outra oportunidade: 1) Como está a efetividade da rotatividade de leitos das unidades hospitalares do município? 2) Há uma demanda de leitos maior do que a oferta na rede? 3) O quanto a agilidade dos resultados dos exames diagnósticos de apoio auxiliaria na conduta médica para alta e/ou regulação do paciente? 4) A gestão da clínica impactou na resolutividade da alta ou permanência do paciente na unidade? 5) As ações das Unidades Básicas de Saúde-UBSs estão sendo efetivas no que tange a prevenção, promoção e disponibilidade de consultas médicas generalista ou especializada? 6) Alguns casos clínicos poderiam ter sido preventivamente tratados via UBS?

As análises empíricas vivenciadas durante este estudo levaram a evidenciar a necessidade de implantação da gestão por processos e gestão da qualidade e segurança do paciente na unidade, seja com base, por exemplo, no tempo de resposta dos exames de imagem e laboratoriais, fluxos e contrafluxos, integração do PEP, gestão da clínica, regulação do paciente, bem como fortalecimento da comunicação em rede com as UBS, ESF, consultas especializadas e rede hospitalar.

Relações essas de suma importância para potencializar e agilizar as ações de cuidado ao paciente, ou seja, a gestão da condição de saúde de forma integral e humanizada dos mesmos permeadas pelo desenvolvimento e sustentabilidade institucional.

Há de se referenciar, também, atenção às questões epidemiológicas dos casos estudados e apresentados conforme classificação CID-10. Os mesmos refletem a saúde coletiva da população Santarena servindo de base para estudos mais aprofundados das políticas públicas. A comunicação entre a UPA como sendo um setor secundário com a Atenção Primária por meio da Estratégia da Saúde da Família e seus Agentes Comunitários de Saúde, por exemplo, é uma ponte eficaz para a continuidade do cuidado e promoção da saúde.

Diante do exposto, espera-se que esse estudo desperte interesses para uma análise dos gestores dos serviços de saúde pública quanto a melhoria na forma que é 
prestado o atendimento. O que visa proporcionar aos usuários do SUS maior qualidade na atenção à saúde, seja individual ou coletiva.

Que outros acadêmicos possam usufruir dos conceitos aqui apresentados e que contribuam em suas carreiras profissionais e formação humana.

A expectativa é que esse trabalho sirva de base para uma análise crítica construtiva para as políticas públicas atuais e futuras de saúde, promoção e prevenção.

\section{REFERÊNCIAS}

BRASIL. DATASUS. Morbidade Hospitalar do SUS - Por local de Internação - Brasil. Disponível em:<http://tabnet.datasus.gov.br/cgi/tabcgi.exe?sih/cnv/nipa.def>. Acesso em: 22/06/2020.

BRASIL.

IBGE.

Disponível em:<https://cidades.ibge.gov.br/brasil/pa/santarem/panorama>. Acesso em: $30 / 09 / 2019$.

BRASIL. Ministério da Saúde. Classificação Estatística Internacional de Doenças e Problemas Relacionados à Saúde. Disponível em: $<$ http://www2.datasus.gov.br/DATASUS/index.php?area=060203>. Acesso em: 28/09/2019.

BRASIL. Ministério da Saúde. SUS: 29 anos garantindo direito à saúde. Disponível em:<http://www.blog.saude.gov.br/index.php/entenda-o-sus/53980-sus-29-anosgarantindo-direto-a-saude>. Acesso em: 25/09/2019.

BRASIL. Ministério da Saúde. Unidade de Pronto Atendimento (UPA 24h): O que é, quando usar, diretrizes e competências. Disponível em:<http://www.saude.gov.br/saude-de-a-z/unidade-de-pronto-atendimento-upa24h>. Acesso em: 20/06/2019. 
BRASIL. Ministério da Saúde. Unidade de Pronto Atendimento (UPA 24h): O que é, quando usar, diretrizes e competências. Disponível em:<http://www.saude.gov.br/saude-de-a-z/componente-hospitalar-da-rede-deatencao-as-urgencias>. Acesso em: 20/06/2019.

BRASIL. Ministério do Planejamento. UPA - Unidade de Pronto Atendimento. Disponível em:<http://pac.gov.br/infraestrutura-social-e-urbana/upa-unidade-depronto-atendimento>. Acesso em: 25/09/2019.

BRASIL. Portal da Enfermagem. Triagem de Manchester - padronização no Pronto Atendimento.

Disponível em:<https://www.portaldaenfermagem.com.br/destaque_read.asp?id=1461>. Acesso em: 28/09/2019.

BRASIL. Portal G1. Um ano e meio após inauguração, UPA entra em funcionamento. Disponível em:<http://g1.globo.com/pa/santarem-regiao/noticia/2014/06/upa-24hinaugura-neste-sabado-em-santarem.html>. Acesso em: 30/09/2019.

BRASIL. Portaria № 1.600 de 7 de julho de 2011. Reformula a Política Nacional de Atenção às Urgências e institui a Rede de Atenção às Urgências no Sistema Único de Saúde (SUS). Brasília, DF: Ministério da Saúde, Gabinete do Ministro, 2011. Disponível em: $<$ https://bvsms.saude.gov.br/bvs/saudelegis/gm/2011/prt1600_07_07_2011.html>. Acesso em: 20/06/2019.

BRASIL. Portaria № 1.601 de 7 de julho de 2011. Estabelece diretrizes para a implantação do componente Unidade de Pronto Atendimento (UPA 24h) e o conjunto de serviços de urgência 24 horas da Rede de Atenção às Urgências, em conformidade com a Política Nacional de Atenção às Urgências. Brasília, DF: Ministério da Saúde, Gabinete do Ministro, 2011. Disponível em: $<$ https://bvsms.saude.gov.br/bvs/saudelegis/gm/2011/prt1601_07_07_2011_rep.html >. Acesso em: 20/06/2019. 
BRASIL. Portaria № 10 de 3 de janeiro de 2017. Redefine as diretrizes de modelo assistencial e financiamento de UPA 24h de Pronto Atendimento como Componente da Rede de Portal da saúde: Atenção às Urgências, no âmbito do Sistema Único de Saúde. Brasília, DF: Ministério da Saúde, Gabinete do Ministro, 2017. Disponível em: <http://bvsms.saude.gov.br/bvs/saudelegis/gm/2017/prt0010_03_01_2017.html>. Acesso em: 20/06/2019.

BRASIL. Portaria no 4.279 de 30 de dezembro de 2010. Estabelece diretrizes para a organização da Rede de Atenção à Saúde no âmbito do Sistema Único de Saúde (SUS). Brasília, DF: Ministério da Saúde, Gabinete do Ministro, 2010. Disponível em: < https://bvsms.saude.gov.br/bvs/saudelegis/gm/2010/prt4279_30_12_2010.html>. Acesso em: 20/06/2019.

BRASIL. Prefeitura de Santarém. História. Disponível em:<http://www.santarem.pa.gov.br/pagina.asp?id_pagina=24>. Acesso em: 30/09/2019.

BRASIL. Resolução № 2.079 de 14 de agosto de 2014. Dispõe sobre a normatização do funcionamento das Unidades de Pronto Atendimento (UPAs) 24h e congêneres, bem como do dimensionamento da equipe médica e do sistema de trabalho nessas unidades. Brasília, DF: Conselho Federal de Medicina. Disponível em:< https://portal.cfm.org.br/images/PDF/resolucao2079. pdf>. Acesso em: 20/06/2019.

BRASIL. Secretaria de Saúde Pública do Pará. 9aㅗ Regional de Saúde. Disponível em:< http://www.saude.pa.gov.br/institucional/centros-regionais-de-saude/9a-regional-desaude/>. Acesso em: 21/09/2019.

BRASIL. Secretaria de Saúde Pública do Pará. Regionais de Saúde. Disponível em:<http://www.saude.pa.gov.br/institucional/centros-regionais-de-saude/>. Acesso em: 22/09/2019.

BRASIL. Tribunal de Contas da União. Auditoria Operacional das Unidades de Pronto Atendimento-UPAs. Brasília, DF: Tribunal de Contas da União, 2012-3. Disponível em: 
https://portal.tcu.gov.br/biblioteca-digital/auditoria-operacional-nas-unidades-depronto-atendimento-upas.htm>. Acesso em 20/06/2019.

BRASIL<http://cnes2.datasus.gov.br/Mod_Ind_Tipo_Leito.asp?VEstado=15\&VMun= 150680 >. Acesso em: 30/09//2019.

BRASIL<http://cnes2.datasus.gov.br/Mod_Ind_Unidade.asp?VEstado=15\&VMun=15 0680 > Acesso em: 25/09/2019.

BRASIL<http://datasus.saude.gov.br/sistemas-e-aplicativos/cadastros-nacionais/cid10>. Acesso em: 30/09/2019.

BRASIL<http://www.datasus.gov.br/cid10/V2008/apresent.htm>. Acesso em: 28/09/2019.

BRASIL<http://www.datasus.gov.br/cid10/V2008/cid10.htm>. Acesso em: 19/09/2019.

BRASIL<https://www.google.com/maps/>. Acesso em: 21/09/2019.

KONDER, Mariana Teixeira, O'DWYER, Gisele. A integração das Unidades de Pronto Atendimento (UPA) com a rede assistencial no município do Rio de Janeiro, Brasil. Interface (Botucatu) [online]. 2016, vol.20, n.59, pp.879-892. ISSN 18075762. https://doi.org/10.1590/1807-57622015.0519. $<$ https://www.scielo.br/scielo.php?pid=S141432832016000400879\&script=sci_abstract\&tIng=pt>. Acesso em: 24/09/2019.

MENDES, Eugênio Vilaça. As Redes de Atenção à Saúde, 2ª edição. Brasília, DF: Organização Pan-Americana da Saúde, 2011. 549 p.:il. Disponível em:<http:/tabnet.datasus.gov.br/cgi/tabcgi.exe?sih/cnv/niuf.def>. Acesso em: 15/06/2020.

VIEIRA, Marilene S. et al. Perfil Epidemiológico dos Pacientes com Doenças Cardiovasculares e Pulmonares atendidos em uma UPA (Unidade de Pronto Atendimento). Curitiba:PR, 2015. Revista Inspirar Movimento e Saúde, Vol. 7 - 
Número 2 - ABR/MAI/JUN - 2015. Disponível em: <https://www.inspirar.com.br/wpcontent/uploads/2015/08/perfil-epidemol-416-v7-n2-2015.pdf>. Acesso em 15/06/2020.

Enviado: Julho, 2020.

Aprovado: Julho, 2020. 